\title{
Taman Vokasi : Pendidikan Tenaga Kerja dengan Konsep Dampak Lingkungan
}

\author{
Poppy Reza Hamanda dan Muhammad Faqih \\ Departemen Arsitektur, Fakultas Teknik Sipil dan Perencanaan, Institut Teknologi Sepuluh Nopember (ITS) \\ e-mail: faqih@arch.its.ac.id
}

\begin{abstract}
Abstrak-Indonesia di tahun 2016 telah memasuki area MEA (Masyarakat Ekonomi Asean) yang berpengaruh pada persaingan tenaga kerja. Namun, disisi lain masyarakat Indonesia sebagian besar belum siap untuk menghadapi MEA dikarenakan banyaknya penduduk Indonesia, tidak memiliki pekerjaan terutama di usia produktif yang dikarenakan kurang adanya keterampilan dalam diri, budaya pilih-pilih pekerjaan, dan lain sebagainya yang mengakibatkan kurang adanya percaya diri. Menurut Badan Pusat Statistik Kota Surabaya, menyebutkan bahwa masih banyaknya tingkat pengangguran yang menyebabkan berbagai dampak negatif, seperti kriminalitas, kejahatan, dan pergaulan bebas yang sebagian besar dilakukan oleh remaja hingga dewasa. Oleh karena itu, penulis mendukung adanya usaha dari pemerintah, yaitu dengan adanya pusat pelatihan kerja di kota Surabaya dan adanya daya dukung untuk mengurangi tekanan yang dimiliki oleh seorang penganggur, melalui segi arsitektural yaitu dengan menggunakan dukungan taman yang dapat mempengaruhi psikologis seseorang. Arsitektur berwawasan perilaku dengan pendekatan psikologis dan konsep dampak lingkungan, diharapkan dapat membantu untuk mengurangi bahkan menyelesaikan masalah yang ada dengan menggunakan metode penyelesaian masalah lingkungan yang menganalisis berbagai aspek yang mengacu pada masalah tersebut.
\end{abstract}

Kata Kunci-Dampak Lingkungan, Pengangguran, Psikologis, Taman, Usia Produktif

\section{PENDAHULUAN}

$\mathrm{M}$ UNCULNYA pengangguran yang ada di kota besar terutama Surabaya, disebabkan karena adanya kemiskinan. Kemisikkinan sendiri memiliki dampak yang kompleks dan berhubungan satu sama lain dengan pangan, kesehatan, pendidikan, dam sebagainya. Dimana dampak dari kemiskinan sendiri sangat dibutuhkan oleh masyarakat terutama kalangan menengah kebawah untuk dapat memenuhi kebutuhan hidup yang lebih baik. Namun, untuk dapat memenuhi kebutuhan tersebut, manusia membutuhkan uang. Sedangkan pada saat ini bekal yang dimiliki oleh masyarakat tidak mencukupi, sehingga banyak masyarakat yang menghalalkan segala cara untuk dapat memenuhi kebutuhan hidupnya.

Tidak hanya disebabkan oleh kemiskinan, namun disisi lain terdapat satu faktor yang pada akhir waktu ini sangat mempengaruhi bagaimana manusia dapat memenuhi kebutuhan hidupnya, yaitu MEA (Masyarakat Ekonomi ASEAN).

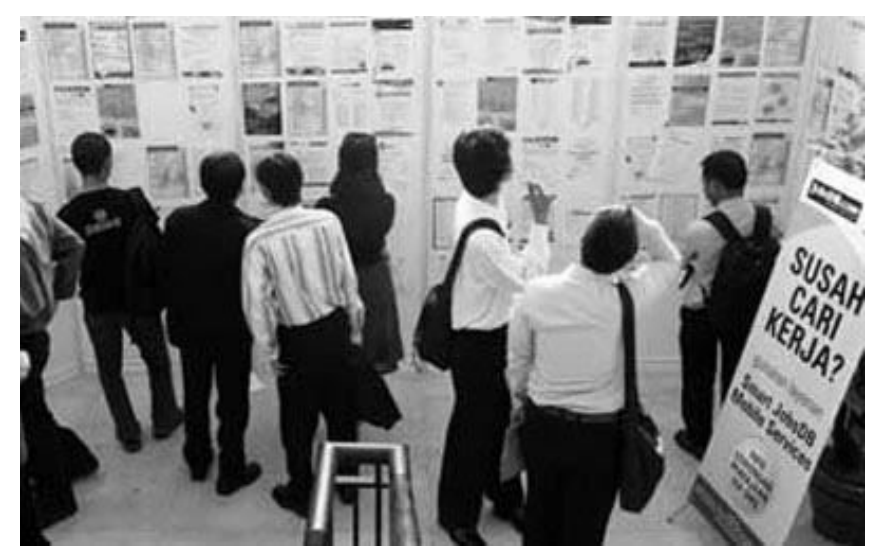

Gambar 1. Ilustrasi Pengangguran.

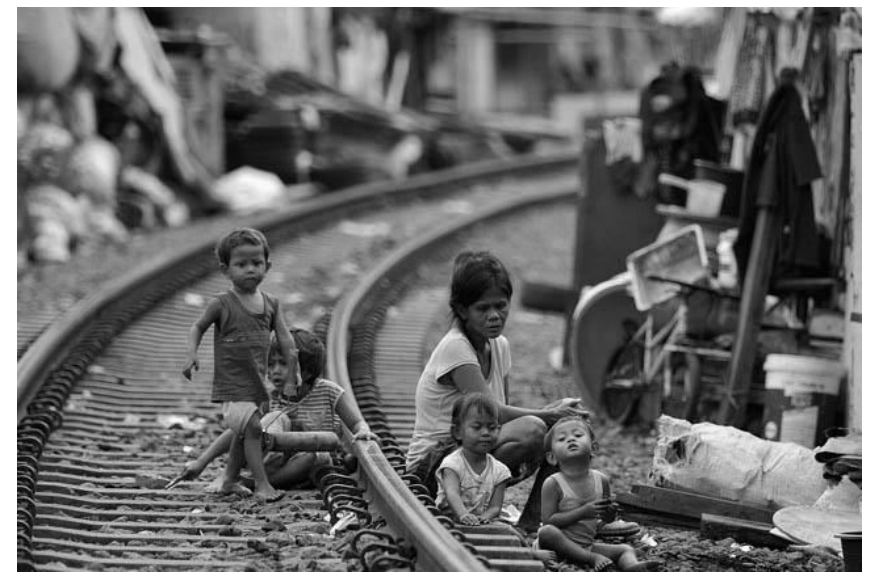

Gambar 2. Ilustrasi Kemiskinan.
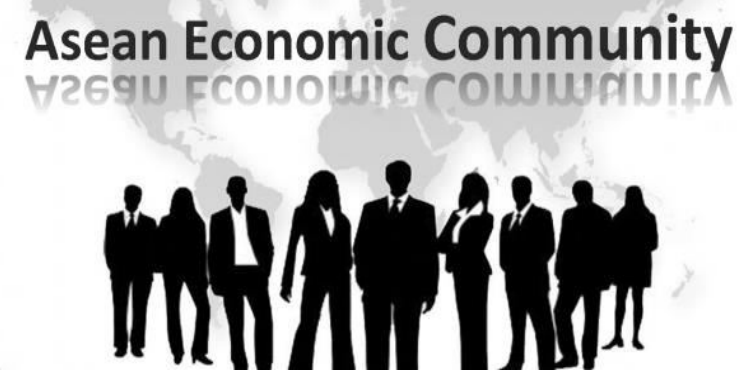

Gambar 3. Masyarakat Ekonomi ASEAN 


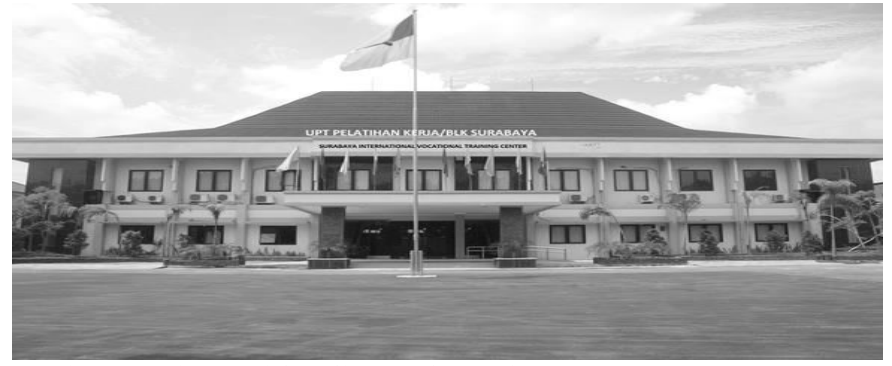

Gambar 4. Gedung Balai Latihan Kerja Surabaya.

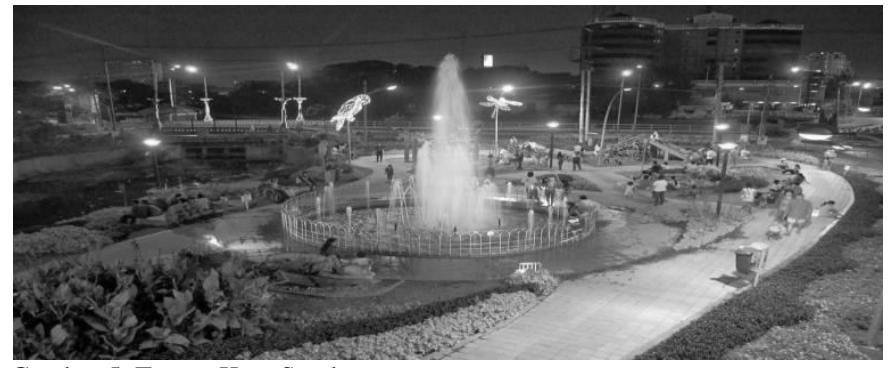

Gambar 5. Taman Kota Surabaya.

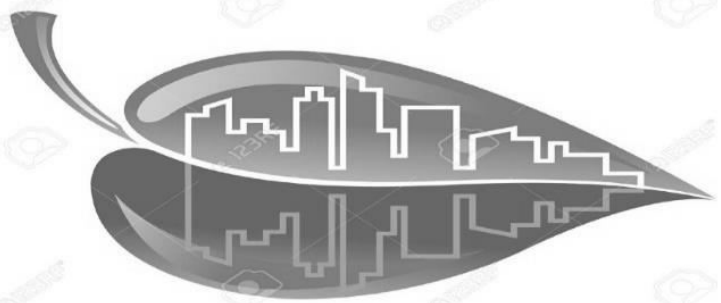

Gambar 6. Ilustrasi Peran Arsitektur dalam Lingkungan.

MEA sendiri memiliki pengaruh dalam hal ketenagakerjaan, dimana masyarakat akan semakin susah mendapatkan pekerjaan, terutama bagi masyarakat yang kurang memiliki bekal pendidikan dan kreatifitas yang ada dalam dirinya. Melihat dampak yang diakibatkan dari adanya pengangguran dan kemiskinan yang dapat mempengaruhi kondisi ekonomi negara dan juga kesejahteraan masyarakat, pada kondisi ini mengharuskan untuk dapat emncari terobosan dan pemechana masalah, agar tenaga kerja sebagai aset bangsa tidak menjadi beban di kemudian hari.

Untuk dapat mengatasi adanya persoalan kesempatan kerja yang terbatas, dibutuhkan adanya fasilitas yang dapat menyeimbangkan antara kebutuhan tenaga kerja pada setiap lowongan pekerjaan yang ada dengan kualitas tenaga kerja dengan standar ketenagakerjaan yang dibutuhkan suuatu perusahaan.

Berdasarkan isu dan konteks desain, respon yang diberikan adalah menciptakan suatu fasilitas yang dapat menampung adanya kegiatan pelatihan secara gratis dan dapat diakses oleh siapapun dan kapanpun, dimana fasilitas tersebut dapat mengurangi adanya rasa tidak layak, ataupun rasa tidak percaya diri; dimana masyarakat juga tidak merasa stress atau juga dapat mereduksi tingkat stress dalam diri seseorang.

Tujuan dari objek rancangan ini adalah menciptakan sebuah fasilitas umum yanng dapat menjadi tempat intetraksi dan rekreasi masyarakat dengan didukung adanya fasilitas dan aktivitas pendidikan, guna meningkatkan produktifitas dan kreatifitas mayarakat.

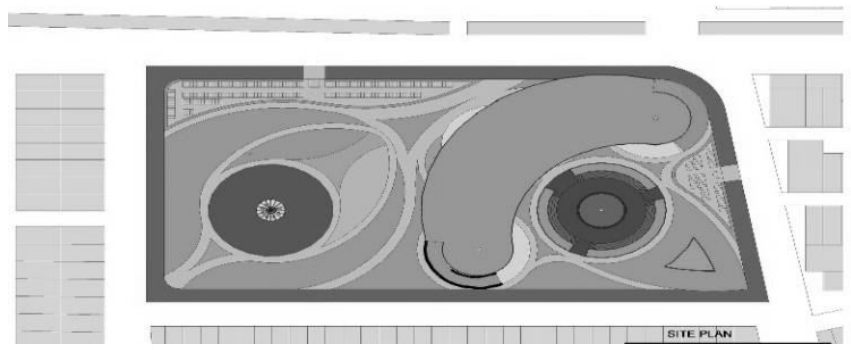

Gambar 7. Siteplan.

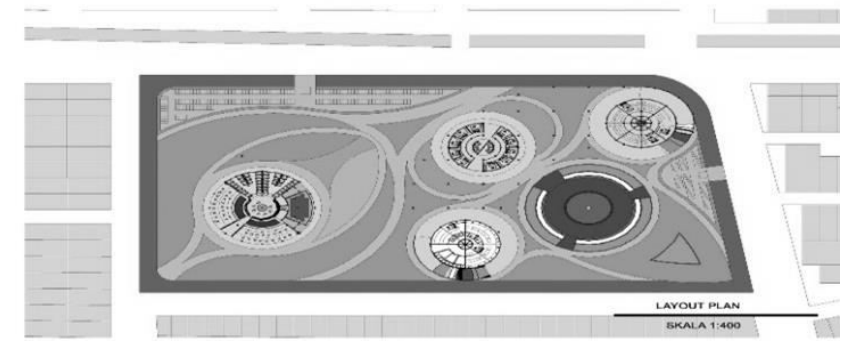

Gambar 8. Layout plan.

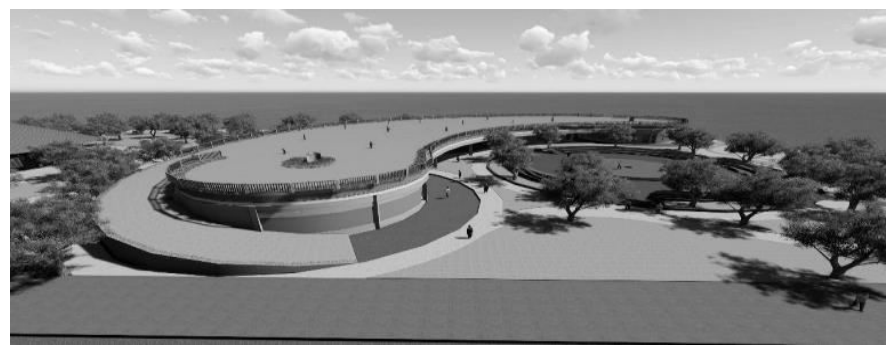

Gambar 9. Perspektif.

Adapun kriteria yang kemudian menjadi acuan desain:

1. Desain dapat mewadahi aktivitas interaksi dan rekreasi warga, serta menarik perhatian warga sekitar, terutama tuna karya.

2. Desain dapat menyatukan antara fasilitas umum dengan sarana pendidikan.

3. Desain dapat mencerminkan karakter kehidupan dan perilaku para remaja tuna karya dengan dampak lingkungan yang akan dibuat.

4. Desain dapat memberikan penanganan terhadap permasalahan dampak pengangguran yang semakin meningkat.

5. Desain sesuai dengan kebutuhan pengguna dan mencerminkan karakteristik tapak.

\section{PENDEKATAN DAN METODE DESAIN}

Pendekatan yang digunakan dalam perancangan, yaitu Psikologis Lingkungan dengan didukung pengamatan sifat dan karakter seorang penganggur di usia produktif. Manusia dan lingkungan merupakan dua faktor yang terus berinteraksi dan saling memengaruhi, perilaku manusia bisa merubah lingkungan, sebaliknya lingkungan sangat berpengaruh bagaimana manusia berperilaku.

1. Lingkungan mengundang dan mendatangkan perilaku

2. Lingkungan membentuk diri

3. Lingkungan memengaruhi citra diri 


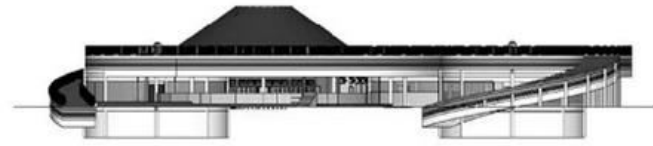

Gambar 10. Tampak Barat

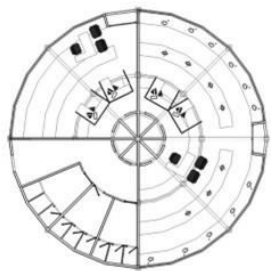

Gambar 11. Denah Jurusan Desain

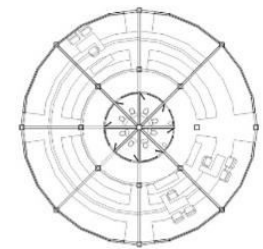

Gambar 12. Denah Jurusan Fisika.

Metode yang digunakan dalam proses desain, menggunakan metode Program Arsitektur, dimana tujuan pemilihan metode ini adalah untuk mencapai tersusunnya desain melalui pendalaman masalah dan pencarian solusi yang tepat secara terstruktur.

Metode yang digunakan dalam pengolahan desain, menggunakan metode transformasi model khusus, dimana metode ini memperhatikan pengolahan massa, struktur bangunan, kesatuan bangunan, penambahan dan pengurangan obyek, hierarki, sirkulasi, geometri, pengulangan, keseimbangan, rencana perletakan massa, pencahayaan.

\section{HASIL DAN EKSPLORASI}

Objek yag dihadirkan berupa ruang terbuka yang ditujukan untuk masyarakat guna relaksasi dan menampung aktivitas yang dapat membantu seseorang untuk dapat mengurangi stres dan tekanan yang dialami oleh individu tersebut, dan didukung adanya fasilitas pendidikan untuk mengasah dan meningkatkan kreatifitas masyarakat dan produktifitasnya.

Konsep yang digunakan dalam rancangan objek ini, yaitu dengan adanya dampak lingkungan yang memberikan pemulihan dalam diri seseorang. Sehingga objek yang dipilih dan yang sesuai dengan konsep yang ada, maka diciptakan adanya taman vokasi yang memiliki prinsip dan elemenelemen yang dapat diterapkan pada objek.

Prinsip penerapan konsep:

1. Desain mampu mendukung proses pemulihan baik fisik maupun psikis seseorang

2. Akses ke alam

3. Adanya kegiatan outdoor yang berhubungan langsung dengan alam

4. Desain diarahkan pada penciptaan kualitas ruang agar suasana terasa aman, nyaman, tidak menimbulkan stres yang berlebih

Manfaat taman dengan konsep dampak lingkungan yanng memulihkan :

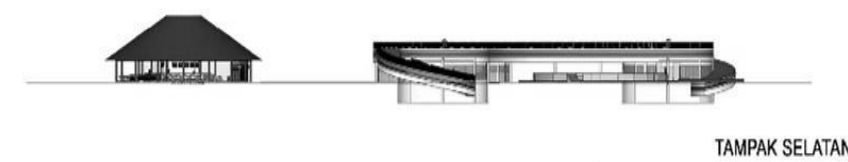

Gambar 13. Tampak Selatan.

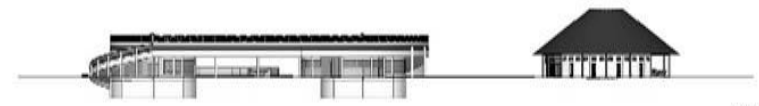

TAMPAKUTARA

Gambar 14. Tampak Utara.

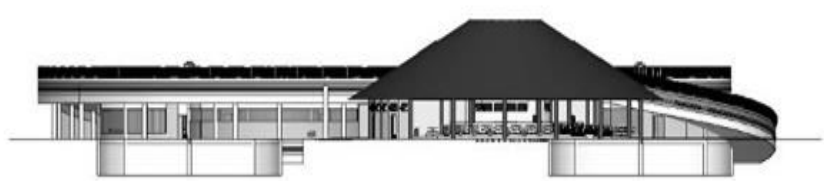

Gambar 15. Tampak Timur.

1. Mengurangi stress pada pengunjung dan staf

2. Mengurangi tingkat depresi pada pengguna

3. Menambah kualitas hidup

4. Mengurangi rasa sakit dalam diri pengguna

5. Menambah kepuasan pengguna

6. Menambah ruang gerak bagi pengguna

Elemen tata ruang, antara lain pencahayaan, warna, pemandangan, suara, aroma, seni, dan tekstur.

\section{KESIMPULAN/RINGKASAN}

Berdasarkan hasil rancangan, bahwa diperlukan adanya ruang terbuka dan ruang gerak teruatama bagi masyarakat yang berada di kota padat dengan aktivitas yang padat, namun juga perlu memperhatikan kebutuhan lingkungan sekitar seperti adanya fasilitas tambahan pendidikan agar ilmu, kreatifitas, dan produktifitas masyarakat semakin meningkat.

\section{DAFTAR PUSTAKA}

[1] Erisanti, Monica. 2015 .. Jurnal Online : "Jadi Pengangguran Bikin Orang Kurang Ramah" [ONLINE] http://indonesiasatu.kompas.com/read/2015/02/21/085544423/Jadi.Pe ngangguran.Bikin.Orang.Kurang.Ramah . Diunduh tanggal 28 September 2016

[2] Gudang Makalah. _. Jurnal Online : "Masalah Pengangguran". [ONLINE] http://www.gudangmakalah.com/2014/11/makalahmasalah-pengangguran-sebab.html . Diunduh tanggal 28 September 2016 Badan Pusat Statistik Kota Surabaya. "Tenaga Kerja" [ONLINE].

[3] https://surabayakota.bps.go.id/Subjek/view/id/6\#subjekViewTab1 . Diunduh tanggal 28 September 2016

[4] Negaraku __. Jurnal Online : "Pengangguran Dapat Merubah Kepribadian Seseorang" [ONLINE] http://www.negaraku.ga/2015/02/pengangguran-dapat-merubahkepribadian.html . Diunduh tanggal 28 September 2016

[5] Kementrian Perindustrian Republik Indonesia. ___. Jurnal Online "Kompetensi SDM Industri". ' [ONLINE] http://www.kemenperin.go.id/kompetensi/ . Diunduh tanggal 28 September 2016

[6] Kementrian Perindustrian Republik Indonesia. __. Jurnal Online : "Standard Kompetensi Kerja Nasional Indonesia". [ONLINE] 
http://www.kemenperin.go.id/kompetensi/skkni_idx.php. Diunduh tanggal 28 September 2016

[7] Surabaya News Update . 2016. Jurnal Online : "Jumlah Pengangguran di Jatim Tercatat 849 Ribu”. [ONLINE] http://surabayanews.co.id/2016/05/17/59354/jumlah-penganggurandi-jatim-tercatat-849-ribu.html . Diunduh tanggal 28 September 2016.

[8] Memo Surabaya. 2016. Jurnal Online : "Angka Pengangguran di Surabaya Membengkak" [ONLINE] http://surabaya.memo- x.com/1731/angka-pengangguran-di-surabaya-membengkak Diunduh tanggal 28 September 2016.

[9] Sutedjo, B. Suwondo. 1986. Jakarta. "Arsitektur, Manusia, dan Pengamatannya". Penerbit Djambatan

[10] Duerk, D. (1993). Architectural Programming: Information Management for Design. New York: Van Nostrand Reinhold.

[11] Jormakka, K. (2008). Basics Design Methods. Basel: Birkhauser. 